\title{
ANTI-INFLAMMATORY AND ANTIOXIDANT PROPERTIES OF ECBALLIUM ELATERIUM FRUIT JUICE AGAINST CYCLOPHPSPHAMIDE INDUCED HEPATOTOXICITY IN RATS
}

\author{
Osama A. Hassan ${ }^{*}$ and Melad G. Paulis ${ }^{* \#}$ \\ *Forensic Medicine and Clinical Toxicology Department, Faculty of Medicine, Minia \\ University, Egypt. \\ \#Internal Medicine Department, Forensic Medicine and Clinical Toxicology Section, Faculty \\ of Medicine, Mut'ah University, Jordan.
}

Corresponding author: Osama A. Hassan, Forensic Medicine \& clinical Toxicology department, Faculty of Medicine, Minia University, Minia, Egypt.

E-mail: hazem13579@yahoo.com.

\begin{abstract}
Background: Cyclophosphamide (CP) is one of the chemotherapeutic and immunosuppressive agents. It has multiple toxic effects, particularly hepatotoxicity. Ecballium elaterium (EE) plant is found in the Mediterranean counties. It has been used as a traditional medicine. Objectives: This work aimed to evaluate the ameliorative effect of EE fruit juice on hepatotoxicity induced by $\mathrm{CP}$ in rats. Material and methods: 28 male rats were divided into equal 4 groups: control group, EE group $(0.2 \mathrm{~mL} / \mathrm{kg}$ orally for 10 days $), \mathrm{CP}$ group ( 2 doses of $150 \mathrm{mg} / \mathrm{kg}$ intraperitoneally in the first 2 days), and EE plus CP group. Biochemical analysis for serum levels of aspartate aminotransferase (AST), alanine aminotransferase (ALT), alkaline phosphatase (ALP), total bilirubin and albumin were carried out. Hepatic oxidant/antioxidant markers; glutathione (GSH), glutathione reductase (GR), superoxide dismutase (SOD), catalase (CAT), and lipid peroxidation product; malondialdehyde (MDA) in addition to pro-inflammatory mediators; tumor necrosis factor- $\alpha$ (TNF- $\alpha$ ), interleukin (IL-1 $\beta$ ) and IL-6 were evaluated. Histopathological examination of the liver was investigated. Results: Serum liver enzymes and total bilirubin were significantly increased with a decrease in albumin in the $\mathrm{CP}$ treated group compared to control group. $\mathrm{CP}$ induced depletion of oxidative stress defensive pathways with increased MDA levels. The examined pro-inflammatory mediators were significantly elevated as compared to control group with disruption of hepatic histopathology. All these hepatic disturbances were ameliorated by administration of EE fruit juice with CP. Conclusion: Administration of EE fruit juice ameliorates the hepatotoxicity induced by $\mathrm{CP}$ through its antioxidant and antiinflammatory activity.
\end{abstract}

Keywords: Cyclophosphamide, Ecballium elaterium, hepatotoxicity, oxidative stress, anti-inflammatory.

\section{INTRODUCTION}

Cyclophosphamide (CP) is a commonly used chemotherapeutic drug having anticancer properties and used for treatment of leukemia, lymphomas, multiple myeloma, in addition to solid tumors (Emadi et al., 2009). In addition, it 
has a role in the treatment of autoimmune diseases and cases of organ transplantation as an immunosuppressive agent (Ge et al., 2018). However, the clinical side effects of CP limit its therapeutic use (Nair et al., 2016). One of the common adverse effects of cyclophosphamide is hepatotoxicity, as it leads to changes in the normal architecture of the liver and changes in hepatic function markers (Lixin et al., 2019).

Cyclophosphamide undergoes metabolic activation within the liver cells by hepatic cytochrome $\mathrm{p} 450$ producing the reactive metabolites phosphoramide mustard and acrolein which leads to free radicals production (Zarei and Shivanandappa, 2013). Physiological and biochemical disturbances have been reported following cyclophosphamide exposure due to oxidative stress (Ghosh et al., 2002). Excess free radicals lead to injury to different cell structures, including proteins and nucleic acids, in addition to lipid peroxidation (Chabra et al., 2014).

Ecballium elaterium (EE) is one of the cucurbitaceous family. It is known as a squirting cucumber. It is abundant in North Africa and South- West Europe and the Mediterranean countries (Greige-Gerges et al., 2007). It grows in Egypt in north Sinai and El-Dabaa (Saker et al., 2012; El Naggar et al., 2015). In Jordan, it is founded in many places, including the waysides and cultured areas (Salhab, 2013). The fruits of the plant contain black seeds and juice. It has been known as a natural remedy for the treatment of several diseases (Raikhlin-Eisenkraft and Bentur, 2000). It has been used as a traditional medicine to treat rhino sinusitis (Uslu et al., 2006). EE also has antimicrobial and anticancer activities (Abbassi et al., 2014; Jacquot et al., 2014).

The current study intended to evaluate the potential ameliorating effect of EE fruit juice on hepatic histopathological and biochemical alterations induced by cyclophosphamide in rats.

\section{MATERIALS AND METHODS}

Cyclophosphamide was obtained as Endoxan ${ }^{\circledR} \quad 200 \mathrm{mg}$ (Baxter, Germany). Ecballium elaterium is known as Faqos el hamir were collected from Tafila, Jordan. The fruit of EE was manually squeezed to collect the juice in glass jars. The juice was filtered twice through $0.45 \mu \mathrm{m}$ filters. The obtained juice was stored in sterile tubes at $-20^{\circ} \mathrm{C}$ (Yiilmaz et al., 2018).

\section{Animals and experimental protocol}

Ten weeks old male Wistar rats $(210 \pm 20 \mathrm{~g})$ were purchased from the Experimental Animal Unit of Minia University. Animals were kept in a good ventilated room at $25 \pm 5$ and $12 \mathrm{~h}$ light/dark cycle. Rats were acclimatized for 10 days before starting the experiment. Animals had free access to standard lab feed and water ad libitum. The study was approved by the Ethical Committee of Faculty of Medicine, Minia University.

The experimental rats were divided into four groups ( 7 rats each) as follows:

Group 1: The control group that received normal saline orally for 10 days (1 $\mathrm{ml} / \mathrm{kg} / \mathrm{day})$ (Shanmugarajan et al., 2008).

Group 2: EE group; rats were administered EE fruit juice at $0.2 \mathrm{~mL} / \mathrm{kg}$ orally once daily for 10 days (El Naggar et al., 2015).

Group 3: CP group, rats were received CP $150 \mathrm{mg} / \mathrm{kg}$ intraperitoneally twice, in the first and second days of the experimental period (10 days) (Shanmugarajan et al., 2008).

Group 4: Rats were administered CP as in group 3, plus EE fruit juice as in group 2.

At the end of the experiment, the animals were sacrificed by cervical dislocation under light ether anesthesia. Blood samples $(0.5 \mathrm{ml})$ were collected via 
cardiac puncture. Samples were centrifuged for 10 minutes at 4,000 rpm. The separated serum samples were used to assess liver function. Immediately after rat's scarification, livers were dissected and removed. Small hepatic samples were fixed in $10 \%$ formalin to be used for histopathological processing. Homogenization was done for other samples $(10 \% \mathrm{w} / \mathrm{v})$ in cold phosphatebuffered saline (PBS) for oxidative stress assessment of the hepatic tissues.

\section{Liver injury assessment}

The following enzymes were measured to assess the degree of liver damage; Serum alanine aminotransferase (ALT), aspartate aminotransferase (AST) and alkaline phosphatase (ALP) levels were tested using commercially available kits (Biosystems, Spain). Liver function was assessed by measuring albumin and total bilirubin using Diamond Diagnostic kits (Egypt) according to (Webster, 1974) and (Suh et al., 2017) respectively.

Measuring inflammatory cytokines

Plasma levels of interleukin-1 beta (IL-1 $\beta$ ), interleukin-6 (IL-6), and tumor necrosis factor alpha (TNF- $\alpha$ ) were measured using enzyme-linked immunosorbent assay (ELISA) kits purchased from (Elabscience, China) following the manufacturer's instructions.

\section{Studying oxidative stress}

The homogenized liver tissue was centrifuged at $9000 \mathrm{~g}$ for $15 \mathrm{~min}$. The separated supernatant was used for oxidative stress assessment. Malondialdehyde (MDA), a lipid peroxidation marker, is commonly used as indicator for oxidative stress. It was measured using the technique of thiobarbituric acid reactive substance and measured as nmol MDA/mg protein (Singh et al., 2018). Glutathione (GSH) content in liver tissues was measured as nmol GSH/mg protein. It was assessed by dithiobis-2-nitrobenzoic acid according to method of Tipple and Rogers (2012).

To analyze antioxidant defense enzymes activities; glutathione reductase (GR), superoxide dismutase (SOD) and catalase (CAT) were assayed. GR activity was evaluated by the method of Carlberg and Mannervik (1975). It depends on the rate of oxidation of NADPH by glutathione disulfide. It was expressed as $\mu$ mol of oxidized NADPH/min/mg protein. SOD and CAT were assessed according to Prakash et al. (2015).

\section{Histopathological study}

The fixed paraffin samples of hepatic tissues were cut into $5 \mathrm{~mm}$ thick sections. The prepared slides were stained with hematoxylin and eosin (H\&E) for light microscopic evaluation. A modified semiquantitative method of Habibi et al., (2015) was used to evaluate histopathological changes in different groups. Three histological changes namely; hepatocyte degeneration, degree of inflammatory cell infiltrate and interstitial hemorrhage, were evaluated. A scoring system was simply applied (0-3). Zero (0) for no change. One, 2, and 3 for mild, moderate, and severe changes respectively. From each examined slide, 3 nonoverlapping fields were assessed for each change, then the mean score for each histopathological parameter was calculated.

Statistical analysis:

Statistical analysis was performed using SPSS v.23. Results were expressed as mean \pm standard deviation (SD). Comparisons between groups were made by one-way ANOVA test followed by Tukey's post-hoc test analysis to compare between individual groups. For statistical analysis of histological examination; Mann-Whitney $U$ test with Bonferroni correction was done. A $\mathrm{P}$ value $<0.05$ was considered significant. 


\section{RESULTS}

Table (1) illustrates the effect of EE fruit juice on liver function of CP-treated group. CP-induced liver damage manifested by significant elevation of AST, ALT, and ALP. EE juice significantly reduced these 3 enzymes concentrations. However, it was still significantly higher than its levels in the control group. Moreover, there was significant increase of serum level of total bilirubin with decreased serum albumin in $\mathrm{CP}$ treated group compared to control group. EE fruit juice induced marked improvement of the liver function in the form of increased serum albumen and reduced total bilirubin in comparing with their concentrations in CP-treated rats.

To test the anti-inflammatory effects of EE fruit juice, TNF- $\alpha$, IL- $1 \beta$, and IL- 6 serum cytokines were assayed. In rats received $\mathrm{CP}$, there was a marked increase in the serum levels of TNF- $\alpha$, IL- $1 \beta$, and IL-6. EE fruit juice treatment in a dose of $0.2 \mathrm{ml} / \mathrm{kg}$ in conjugation with $\mathrm{CP}$ administration restored the normal concentrations of these circulatory cytokines. TNF- $\alpha$, IL-1 $\beta$, and IL-6 levels showed insignificant changes in rats received $\mathrm{EE}$ fruit juice with $\mathrm{CP}$ when compared with their levels in the control group (Fig. 1).

Studying the oxidative stress markers, enzymatic and non-enzymatic, showed that $\mathrm{CP}$ increased reactive oxygen species. There was an increase in the lipid peroxidation manifested by significantly elevated MDA level in liver tissue of rats. EE fruit juice succeeded significantly to protect the liver cells from $\mathrm{CP}$-induced lipid peroxidation as there was a significant reduction in MDA level in hepatic tissue in rats received $\mathrm{EE}$ fruit juice plus CP. However, MDA did not return to its normal level. In a similar manner, Moreover, CP exhausted oxidative stress defensive pathways. GSH content and antioxidative stress enzymes GR, CAT, and
SOD were significantly decreased in rat's liver received $\mathrm{CP}$. EE fruit juice coingestion reversed this toxic effect of CP. CAT and GR returned to their normal levels by EE fruit juice coadministration, while GSH content and SOD were still significantly higher in comparing with that of control rats. However, GSH and SOD levels were significantly improved by EE fruit juice (Fig. 2).

Microscopic examination of hepatic tissues of rats received saline or EE fruit juice $0.2 \mathrm{ml} / \mathrm{kg}$ showed normal hepatic structure (Fig. 3). Segments from the liver of CP-treated animals demonstrated marked histological changes in the form of loss of normal hepatic architecture, marked inflammatory cells infiltrate and areas of hemorrhages. There were marked hepatocytes vaculations, increased number of pyknotic nuclei and necrosis (Fig. 4). Fig. (5) illustrates that $\mathrm{EE}$ fruit juice restored mostly the normal structure of the hepatic tissue when administered with CP. $\mathrm{CP}$ plus $\mathrm{EE}$ fruit juice treated group showed a lesser degree of inflammatory cell infiltrate, minimal hemorrhage, and decreased hepatocyte vaculations.

Table (2) demonstrated the results of the histopathological assessment of the hepatic tissue of diverse groups using the semiquantitative method. The results of this method go in line with the ordinary histopathological examination. CP-induced significant pathological changes regarding the 3 examined parameters. However, EE fruit juice congestion with $\mathrm{CP}$ significantly improved these pathological changes. 
Table (1): Effect of Ecballium elaterium (EE) and Cyclophosphamide (CP) on liver function parameters of rats (mean \pm SD)

\begin{tabular}{|l|l|l|l|l|}
\hline \multicolumn{1}{|c|}{ Groups } & Control & EE group & CP group & EE+CP group \\
\hline Parameters & & & & \\
\hline AST (U/L) & $43.2 \pm 3.1$ & $45.6 \pm 4.7$ & $82.7 \pm 6.1^{*}$ & $52.8 \pm 6.7^{* \#}$ \\
\hline ALT (U/L) & $28.6 \pm 3.8$ & $24.1 \pm 3.2$ & $62.6 \pm 8.2^{*}$ & $43.2 \pm 5.0^{* \#}$ \\
\hline ALP (U/L) & $33.8 \pm 4.1$ & $31.2 \pm 4.4$ & $56.6 \pm 7.1^{*}$ & $39.5 \pm 6.2^{* \#}$ \\
\hline Albumin (mg/dl) & $4.34 \pm 0.90$ & $4.12 \pm 0.7$ & $2.76 \pm 0.61^{*}$ & $3.56 \pm 0.72^{* \#}$ \\
\hline $\begin{array}{l}\text { Total bilirubin } \\
\text { (mg/dl) }\end{array}$ & $0.82 \pm 0.08$ & $0.91 \pm 0.07$ & $2.31 \pm 0.15^{*}$ & $1.25 \pm 0.17^{\text {*\# }}$ \\
\hline
\end{tabular}

SD: Standard deviation

AST: Aspartate aminotransferase

ALT: Alanine aminotransferase

ALP: Alkaline phosphatase

EE group: rats treated with $0.2 \mathrm{ml} / \mathrm{kg}$ EE fruit juice orally for 10 days. $\mathrm{CP}$ group: rats treated with $\mathrm{CP}, 150 \mathrm{mg} / \mathrm{kg}$ intraperitoneally for 2 doses. $\mathrm{CP}+\mathrm{EE}$ group: rats treated with both $\mathrm{EE}$ fruit juice and $\mathrm{CP}$ with similar doses as in $\mathrm{EE}$ and $\mathrm{CP}$ groups. *

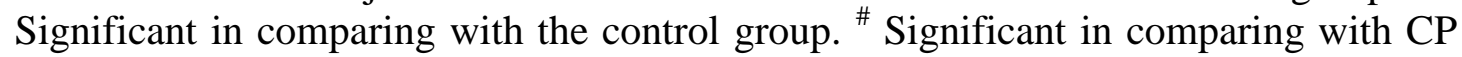
group. $\mathrm{P}<0.05$.

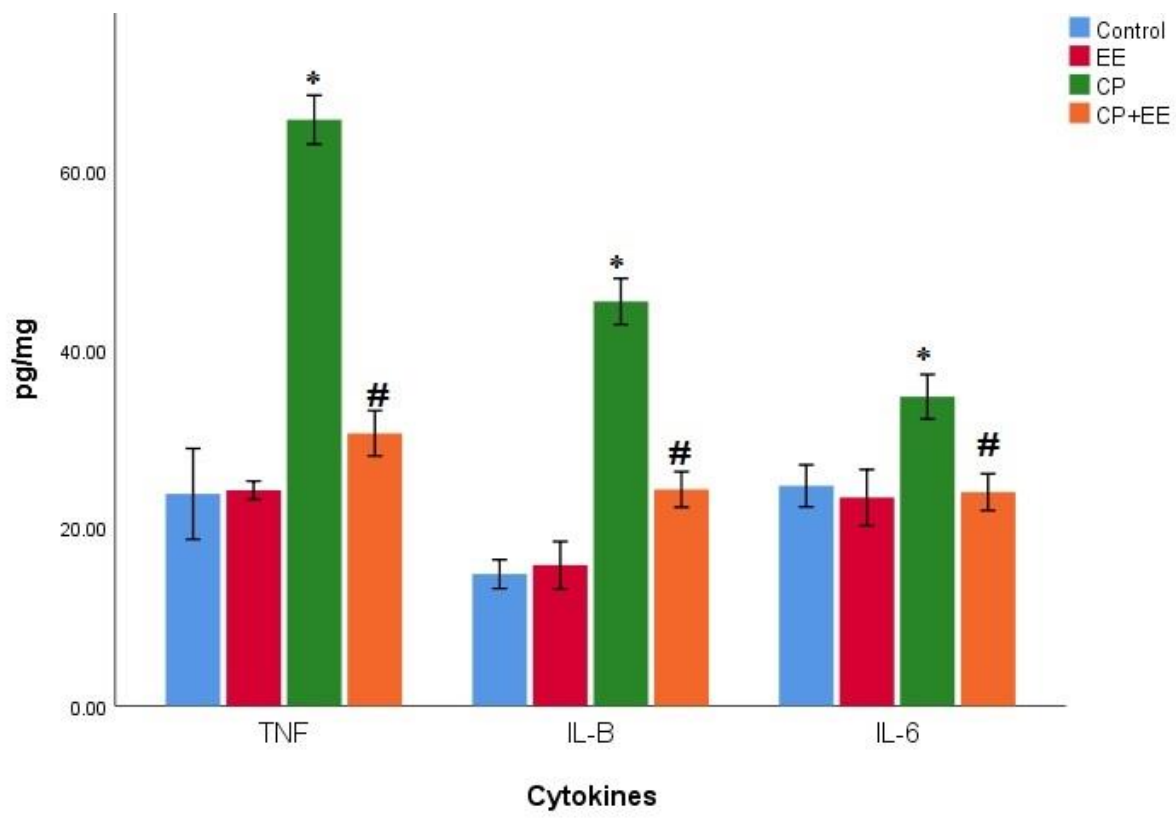

Fig. (1): Effect of Ecballium elaterium (EE) and Cyclophosphamide (CP) on serum inflammatory cytokines. EE group: rats treated with $0.2 \mathrm{ml} / \mathrm{kg}$ EE fruit juice orally for 10 days. CP group: rats treated with $\mathrm{CP} 150 \mathrm{mg} / \mathrm{kg}$ intraperitoneally for 2 doses. $\mathrm{CP}+\mathrm{EE}$ group: rats treated with both $\mathrm{EE}$ fruit juice and $\mathrm{CP}$ with similar doses as in $\mathrm{EE}$ and $\mathrm{CP}$ groups. TNF- $\alpha$ : tumor necrosis factor alpha, IL-1B: interleukin-1 beta. IL-6: interleukin6 . Data were expressed as mean $\pm \mathrm{SD}$. * significant in comparing with the control group. \# Significant in comparing with CP group. $\mathrm{P}<0.05$. 

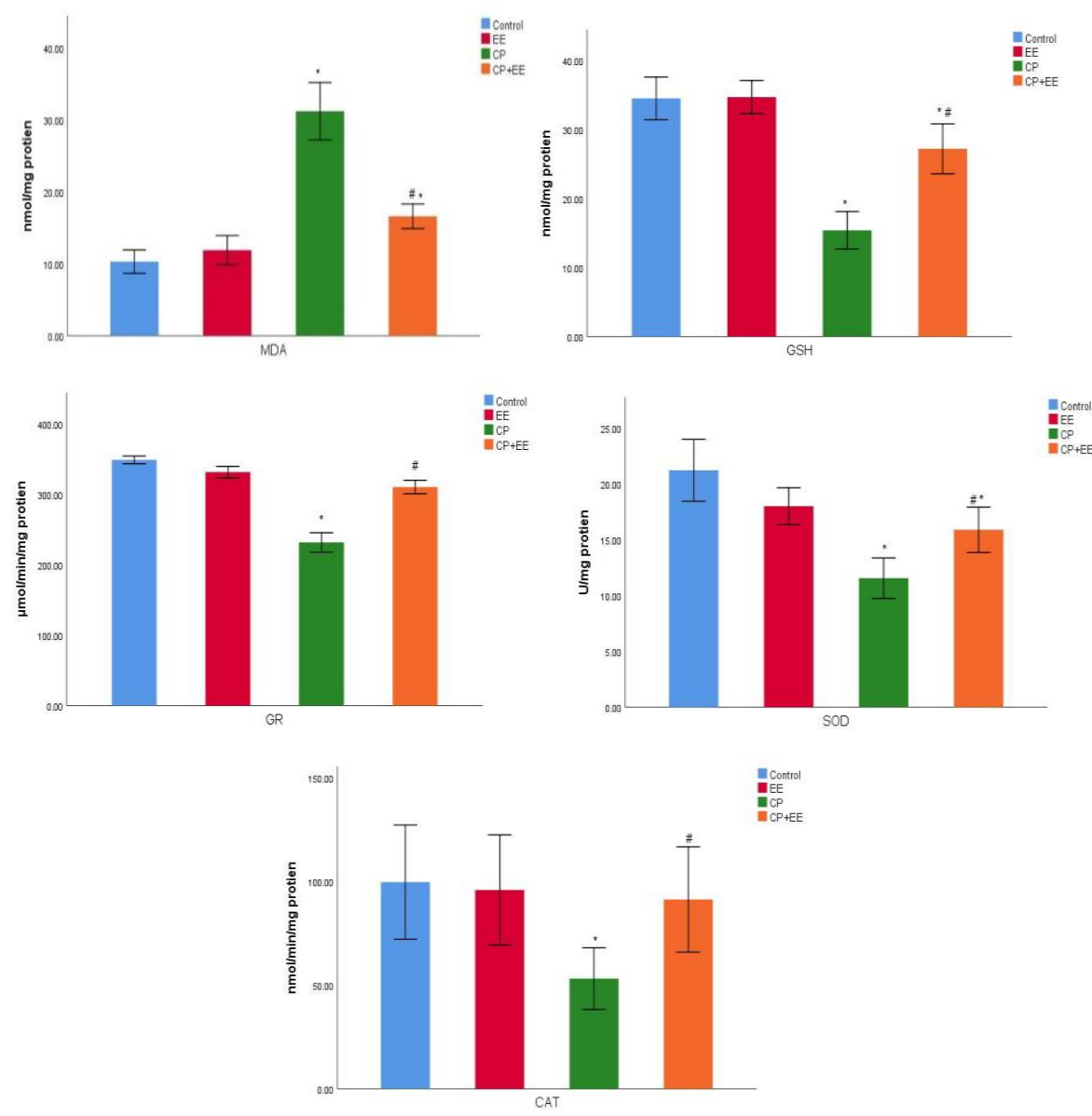

Fig. (2): shows the effect of Ecballium elaterium (EE) and Cyclophosphamide (CP) on the oxidative system of rat liver. EE group: rats treated with $0.2 \mathrm{ml} / \mathrm{kg}$ EE fruit juice orally for 10 days. CP group: rats treated with CP150 mg/kg intraperitoneally for 2 doses. $\mathrm{CP}+\mathrm{EE}$ group: rats treated with both $\mathrm{EE}$ fruit juice and $\mathrm{CP}$ with similar doses as in $\mathrm{EE}$ and CP groups. MDA: malondialdehyde. GSH: glutathione content. GR: glutathione reductase. SOD: superoxide dismutase. CAT: catalase. Data were expressed as mean \pm SD. * Significant in comparing with the control group. \# Significant in comparing with $\mathrm{CP}$ group. $\mathrm{P}<0.05$.
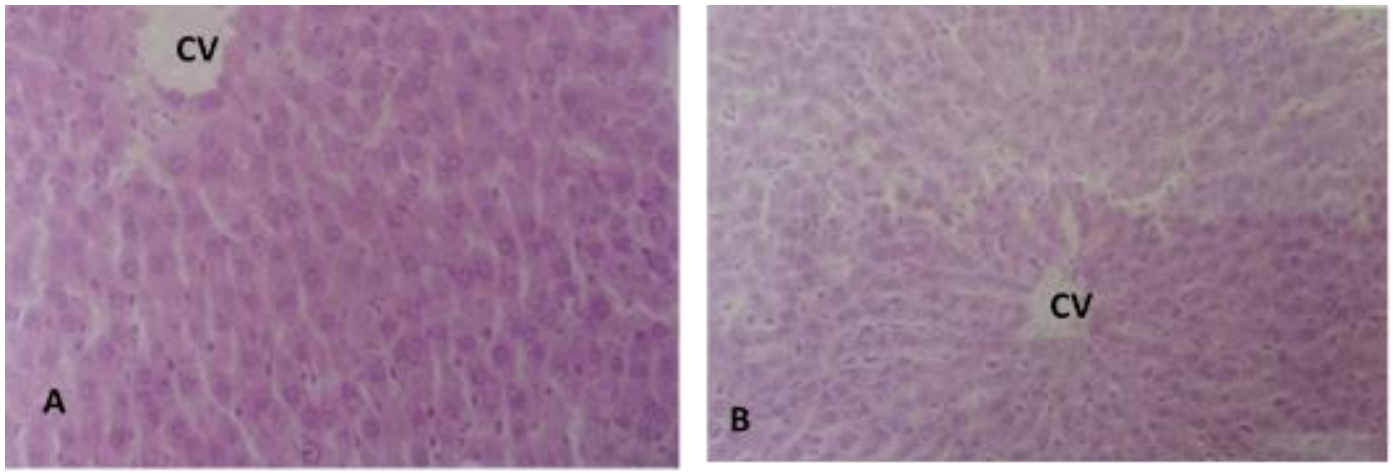

Fig. (3): Photomicrograph of groups that received saline (A) or Ecballium elaterium (B) showed normal hepatic structure. CV: central vein (H\&E, X400). 

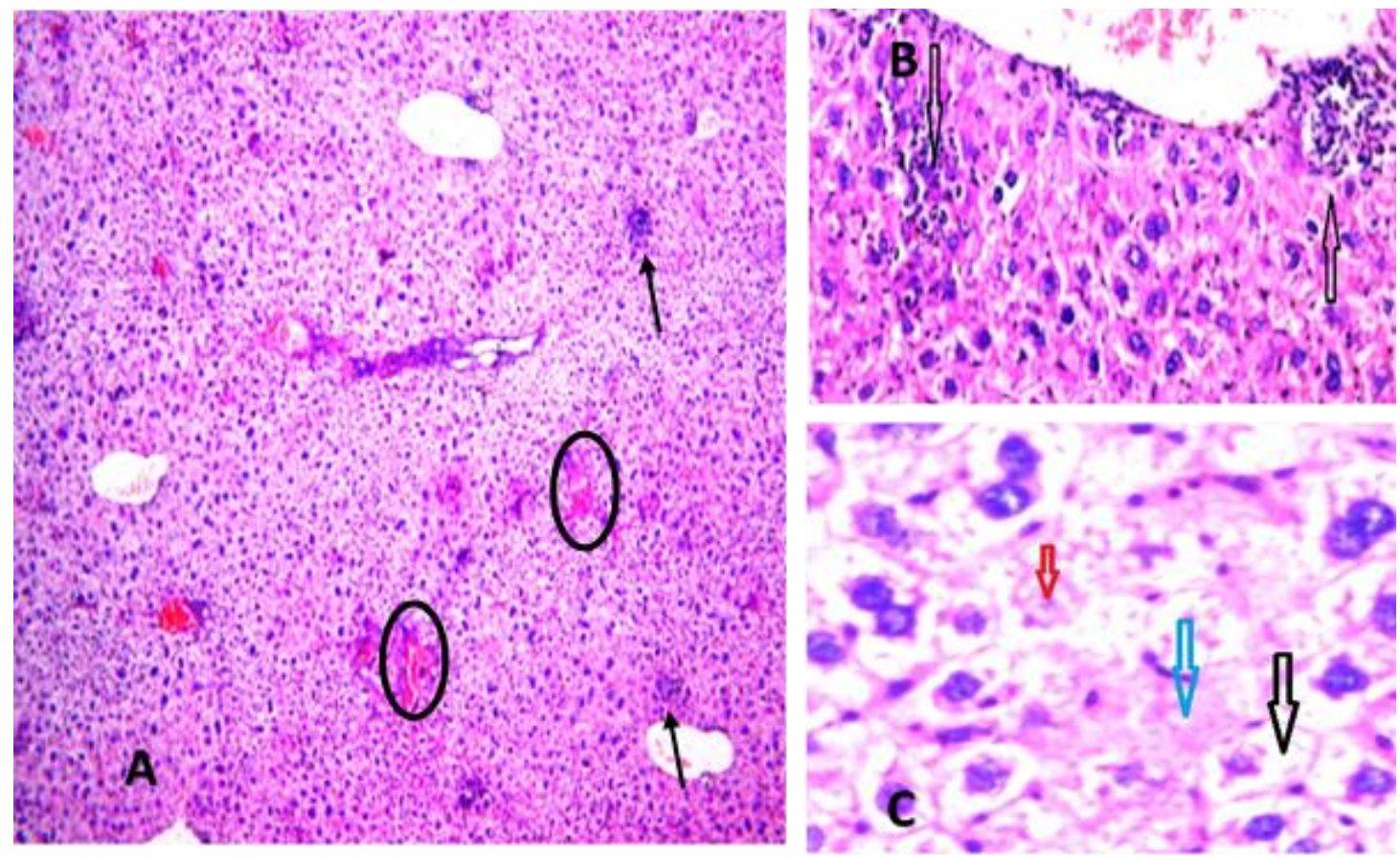

Fig. (4): Cyclophosphamide treated group showed A) loss of normal hepatic architecture, marked inflammatory cells infiltrate (arrows) and areas of hemorrhages (circles). B) areas of cellular infiltrates. C) hepatocytes vaculations (black arrow), pyknotic nuclei (red arrow) and necrosis (blue arrow). (H\&E, A, B, C, X200, X400, X400).

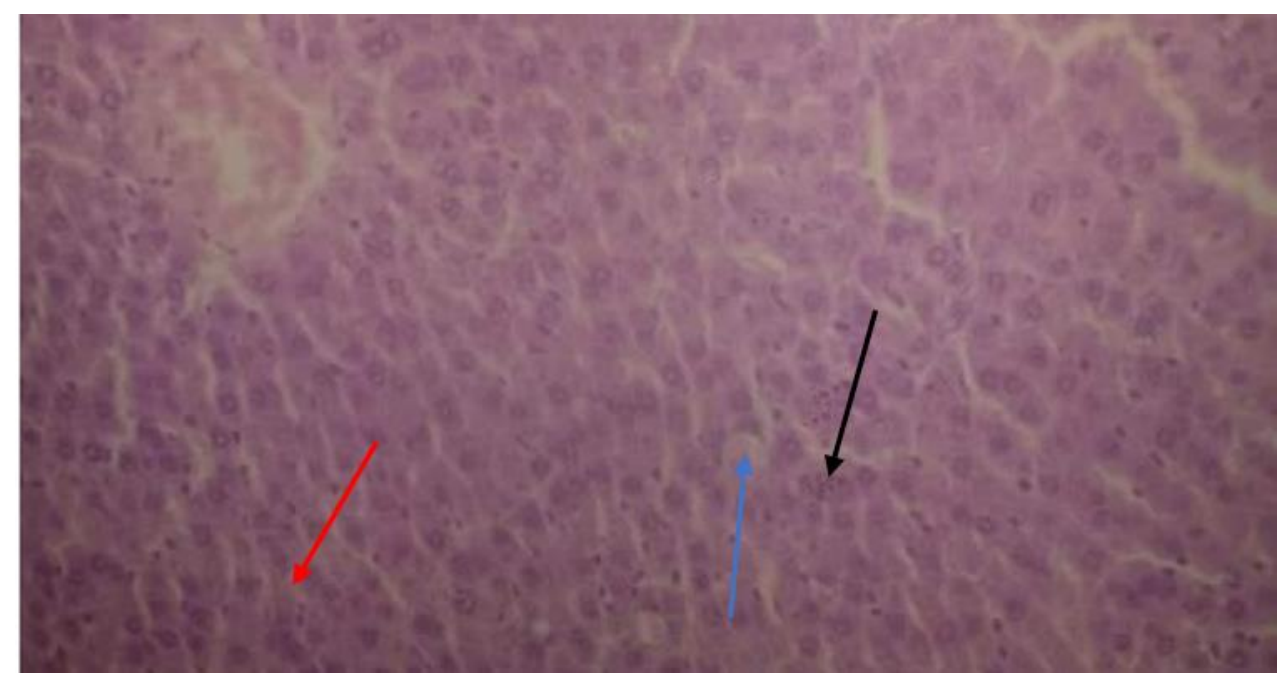

Fig. (5): Ecballium elaterium plus Cyclophosphamide- treated group showed restored normal hepatic architecture with a lesser degree of inflammatory cell infiltrate (black arrow), minimal hemorrhage (red arrow), and minimal vaculations (blue arrow) (H\&E, X400). 
Table (2): Effect of Ecballium elaterium (EE) and Cyclophosphamide (CP) on histopathological changes of liver of rats (mean $\pm \mathrm{SD}$ ). EE group: rats treated with $0.2 \mathrm{ml} / \mathrm{kg}$ EE fruit juice orally for 10 days. CP group: rats treated with $\mathrm{CP}$, $150 \mathrm{mg} / \mathrm{kg}$ intraperitoneally for 2 doses. EE + CP group: rats treated with both $\mathrm{EE}$ fruit juice and $\mathrm{CP}$ with similar doses as in EE and CP groups. Data were expressed as mean \pm SD. Score coding: $0,1,2$, and 3 for no, mild, moderate, and server changes. * Significant in comparing with the control group. "Significant in comparing with $\mathrm{CP}$ group. Significant at $\mathrm{P}<0.05$.

\begin{tabular}{|c|c|c|c|c|}
\hline $\begin{array}{l}\text { Groups } \\
\text { Pathological changes }\end{array}$ & Control & EE group & CP group & $\begin{array}{l}\mathrm{EE}+\mathrm{CP} \\
\text { group }\end{array}$ \\
\hline Hepatocyte degeneration & $0 \pm 0.62$ & $0 \pm 0.62$ & $2 \pm 0.85^{*}$ & $1 \pm 0.71^{* \#}$ \\
\hline $\begin{array}{l}\text { Inflammatory cells } \\
\text { infiltrate }\end{array}$ & $0 \pm 0.43$ & $0 \pm 0.43$ & $3 \pm 0.56^{*}$ & $1 \pm 0.51^{* \#}$ \\
\hline Interstitial hemorrhage & $0 \pm 0.22$ & $0 \pm 0.31$ & $3 \pm 0.21^{*}$ & $1 \pm 0.34^{* \#}$ \\
\hline
\end{tabular}

SD: Standard deviation

\section{DISCUSSION}

Cyclophosphamide is one of the effective drugs for treatment of different types of neoplasms and autoimmune diseases. It is widely used nowadays for different diseases (Moutsopoulos et al., 2018; Phillips et al., 2019). However, the severe adverse effects and tissue injury induced by CP make a giant obstacle in its use (Eichhorst et al., 2016). One of these severe adverse effects of Cyclophosphamide that could restrict its usage is hepatotoxicity (Selvakumar et al., 2006). There are a wide range of natural and synthetic substances that have been studied to counteract the toxic effects of CP (Khedret et al., 2015; El-Kholy et al., 2017). Ecballium elaterium is a Mediterranean plant that is used in folk and non-folk medicine for numerous medical situations (Okur et al., 2014; Arslan et al., 2016). There are few data regarding the protective effect of $\mathrm{EE}$ on hepatotoxicity induced by drugs and toxic agents. Two studies have been used animal model for studying the potential role of $\mathrm{EE}$ fruit juice as a protective agent against paracetamol and $\mathrm{CCl}_{4}$ hepatotoxicity (EImhdwi et al., 2014; El Naggar et al., 2015). So, the current study was planned to assess the attenuating effect of EE fruit juice on hepatotoxicity induced by cyclophosphamide in rats.

In the present study, administration of $\mathrm{CP}$ to rats led to an elevation of the serum levels of hepatic biomarkers, AST, ALT and ALP in addition to increased serum level of total bilirubin and decreased albumin; indicating hepatic dysfunction and damage induced by $\mathrm{CP}$. The increased serum levels of AST, ALT and ALP are indicators of hepatocellular damage (Kumar et al., 2005). Determination of albumin and bilirubin levels are important indicators of hepatic function evaluation (Tothova et al., 2016). So, the changes in their levels are pointers of hepatic dysfunction following CP exposure. These 
results are in line with several previous studies (Basu et al., 2015; Fouad et al., 2016; Ali, 2018). In the present study, authors found that administration of EE fruit juice led to attenuation of these changes by decreasing the elevated hepatic enzymes. This ameliorating effect may be due that EE juice stabilizes cell membrane preventing leakage of these enzymes intracellular. Moreover, EE fruit juice improved liver function which reflected on increased serum albumin and declined total bilirubin. These results agree with the same findings of Elmhdwi et al. (2014) And El Naggar et al. (2015).

Previous studies reported that oxidative stress is one of the key explanations of hepatotoxicity induced by CP (Zarei and Shivanandappa, 2013; Fouad et al., 2016). CP leads to production of two reactive metabolites; phosphoramide mustard and acrolein through activation by cytochrome p450. Acrolein metabolite leads to reactive oxygen species generation (Liu et al., 2012). In our current study $\mathrm{CP}$ administration to rats, induced reduction in the activity of the antioxidant enzymes; SOD, CAT and GR in addition to GSH. There was an increase in lipid peroxidation marker MDA in liver tissues which indicates occurrence of oxidative stress. The significant reduction of the nonenzymatic antioxidant GSH and enzymatic antioxidants SOD, CAT and GR in hepatic tissues of rats may be due to conjugation of $\mathrm{CP}$ and its metabolites to $\mathrm{SH}$ groups (Basu et al., 2015). Administration of $E E$ fruit juice counteracted the oxidative stress effect of CP. MAD, GSH, GR, SOD, and CAT in hepatic tissues of rats received both $\mathrm{CP}$ and EE have significantly changed from its levels in rats treated with $\mathrm{CP}$ alone. It is worthy to mention that GR and CAT were restored to its levels in control rats. MAD, GSH, and SOD levels were significantly changed from their levels in rats received $\mathrm{CP}$ but they did not return to their normal concentration (its levels remained significantly differ from that of control rats). Our results agreed with other previous studies that reported antioxidant activity of EE (Elmhdwi et al., 2014; Felhi et al., 2017).

Moreover, CP treatment induced elevation of the pro-inflammatory cytokine's TNF- $\alpha$, IL- $1 \beta$ and IL- 6 in serum of rats, which indicates increased inflammatory response. This result coincides with other previous studies (Korkmaz et al., 2007; Hamsa and Kuttan, 2012). The supplementation of EE fruit juice significantly decreased the hepatic expression of the pro-inflammatory cytokines; TNF- $\alpha, \quad$ IL- $1 \beta$ and IL6 , indicating its important ameliorating role against $\mathrm{CP}$ induced inflammatory response in the liver. This result supports other previous studies that has been reported the anti-inflammatory effect of EE (Yesilada et al., 1989).

Histopathological examination of rat liver of different groups goes in line with biochemical changes of the examined animals. CP treated rats showed hepatic vaculations, necrosis, cellular infiltration and interstitial hemorrhage. These structural changes of the hepatic tissue were alleviated by the use of the EE juice with only mild changes. This protective effect of EE on liver cells was also, proved against paracetamol and carbon tetrachloride (Elmhdwi et al., 2014; El Naggar et al., 2015).

It is reported that EE has a strong antiinflammatory effect in various tissues. This anti-inflammatory action is due to its abundance of flavonoids and tannins (Felhi et al., 2017). Flavonoids are known to have anti-inflammatory action (Nile et al., 2018). The antioxidant ability of EE could be presumably related to the phenolic compounds. Phenolics have potent antioxidant properties by acting as electron donors that fight free radicals (Nile et al., 2018). In addition, flavonoids and tannins have antioxidant activities (Halliwell et 
al., 1995). In this study, EE fruit juice restored the examined cytokines to their normal levels as that of the normal group. However, EE failed to do so with all the tested antioxidant markers (GR and CAT returned to their normal levels and MDA, GSH, and SOD remained high than that of control rats). These results may indicate that $\mathrm{EE}$ have a more potent antiinflammatory effect than its antioxidant properties.

\section{CONCLUSION}

We concluded that Ecballium elaterium fruit juice ameliorates the detrimental effects of hepatotoxicity induced by Cyclophosphamide through its anti-inflammatory and antioxidant effects.

\section{RECOMMENDATIONS}

- Further studies about the hepatoprotective effects of Ecballium elaterium are recommended.

- Ecballium elaterium fruit juice may have a valuable protective effect against hepatotoxicity induced by $\mathrm{CP}$ in the clinical practice.

\section{REFERENCES}

Abbassi, F.; Ayari, B.; Mhamdi, B. \& Toumi, L. (2014): Phenolic contents and antimicrobial activity of squirting cucumber (Ecballium elaterium) extracts against food-borne pathogens. Pakistan journal of pharmaceutical sciences, 27: 475-479.

Ali, A.H.A. (2018): Hepatoprotective Effect of Green Tea Extract against Cyclophosphamide Induced Liver Injury in Albino Rats. Forensic Medicine and Anatomy Research, 6(2): 11-19.

Arslan, M.S.; Basuguy, E.; Ibiloglu, I.; Bozdemir, E.; Zeytun, H.; Sahin, A. et al. (2016): Effects of Ecballium elaterium on proinflammatory cytokines in a rat model of sepsis. Journal of Investigative Surgery, 29: 399-404.

Basu, A.; Bhattacharjee, A.; Samanta, A. \& Bhattacharya, S. (2015): Prevention of cyclophosphamideinduced hepatotoxicity and genotoxicity: effect of an L-cysteine based oxovanadium (IV) complex on oxidative stress and DNA damage. Environmental toxicology and pharmacology, 40: 747-757.

Carlberg, I. \& Mannervik, B. (1975): Purification and characterization of the flavoenzyme glutathione reductase from rat liver. Journal of biological chemistry, 250: 5475-5480.

Chabra, A.; Shokrzadeh, M.; Naghshvar, F.; Salehi, F. \& Ahmadi, A. (2014): Melatonin ameliorates oxidative stress and reproductive toxicity induced by cyclophosphamide in male mice. Human \& experimental toxicology, 33: 185-195.

Eichhorst, B.; Fink, A.M.; Bahlo, J.; Busch, R.; Kovacs, G.; Maurer, C. et al. (2016): First-line chemoimmunotherapy with bendamustine and rituximab versus fludarabine, cyclophosphamide, and rituximab in patients with advanced chronic lymphocytic leukaemia (CLL10): an international, open-label, randomised, phase 3, non-inferiority trial. The lancet oncology, 17: 928942.

El-Kholy, A.A.; Elkablawy, M.A. \& ElAgamy, D.S. (2017): Lutein mitigates cyclophosphamide induced lung and liver injury via NF- $\kappa \mathrm{B} / \mathrm{MAPK}$ dependent mechanism. Biomedicine \& Pharmacotherapy, 92:519-527.

El Naggar, E.M.B.; Chalupová, M.; Pražanová, G.; Parák, T.; Švajdlenka, E.; Žemlička, M. \& Suchý, P. (2015): Hepatoprotective and proapoptotic effect of Ecballium elaterium on CCl4-induced hepatotoxicity in rats. Asian Pacific 
Journal of Tropical Medicine, 8: 526531.

Elmhdwi, M.F.; Muftah, S.M. \& Elslimani, F.A. (2014): Hepatoprotective effect of Ecballium Elaterium fruit juice against paracetamol induced hepatotoxicity in male albino rats. International Current Pharmaceutical Journal, 3: 270-274.

Emadi, A.; Jones, R.J. \& Brodsky, R.A. (2009): Cyclophosphamide and cancer: golden anniversary. Nature reviews Clinical oncology, 6 (11): 638-647.

Felhi, S.; Daoud, A.; Hajlaoui, H.; Mnafgui, K.; Gharsallah, N. \& Kadri, A. (2017): Solvent extraction effects on phytochemical constituents profiles, antioxidant and antimicrobial activities and functional group analysis of Ecballium elaterium seeds and peels fruits. Food Science and Technology, 37(3): 483-492.

Fouad, A.A.; Qutub, H.O. \& Al-Melhim, W.N. (2016): Punicalagin alleviates hepatotoxicity in rats challenged with cyclophosphamide. Environmental toxicology and pharmacology, 45: 158-162.

Ge, B.; Yang, D.; Wu, X.; Zhu, J.; Wei, W. \& Yang, B. (2018): Cytoprotective effects of glycyrrhetinic acid liposome against cyclophosphamide-induced cystitis through inhibiting inflammatory stress. International immunopharmacology, 54: 139-144.

Ghosh, D.; Das, U.; Ghosh, S.; Mallick, M. \& Debnath, J. (2002): Testicular gametogenic and steroidogenic activities in cyclophosphamide treated rat: a correlative study with testicular oxidative stress. Drug and chemical toxicology, 25: 281-292.

Greige-Gerges, H.; Khalil, R.A.; Mansour, E.A.; Magdalou, J.; Chahine, R. \& Ouaini, N. (2007): Cucurbitacins from Ecballium elaterium juice increase the binding of bilirubin and ibuprofen to albumin in human plasma. Chemico-Biological Interactions, 169: 53-62.

Habibi, E.; Shokrzadeh, M.; Chabra, A.; Naghshvar, F.; Keshavarz-Maleki, R. \& Ahmadi, A. (2015): Protective effects of Origanum vulgare ethanol extract against cyclophosphamideinduced liver toxicity in mice. Pharmaceutical biology, 53: 10-15.

Halliwell, B.; Aeschbach, R.; Löliger, J. \& Aruoma, O. (1995): The characterization of antioxidants. Food and Chemical Toxicology, 33: 601617.

Hamsa, T. \& Kuttan, G. (2012): Tinospora cordifolia ameliorates urotoxic effect of cyclophosphamide by modulating GSH and cytokine levels. Experimental and toxicologic Pathology, 64: 307-314.

Jacquot, C.; Rousseau, B.; Carbonnelle, D.; Chinou, I.; Malleter, M.; Tomasoni, C. \& Roussakis, C. (2014): $\quad$ Cucurbitacin-D-induced CDK1 mRNA up-regulation causes proliferation arrest of a non-small cell lung carcinoma cell line (NSCLC-N6). Anticancer research, 34: 4797-4806.

Khedr, N.F. (2015): Protective effect of mirtazapine and hesperidin on cyclophosphamide-induced oxidative damage and infertility in rat ovaries. Experimental Biology and Medicine, 240: 1682-1689.

Korkmaz, A.; Topal, T. \& Oter, S. (2007): Pathophysiological aspects of cyclophosphamide and ifosfamide induced hemorrhagic cystitis; implication of reactive oxygen and nitrogen species as well as PARP activation. Cell biology and toxicology, 23: 303-312.

Kumar, G.; Banu, G.S.; Kannan, V. \& Pandian, M.R. (2005): Antihepatotoxic effect of $\beta$-carotene on paracetamol induced hepatic damage in rats. Ind $\mathbf{J}$ Exp Biol 43:351-355. 
Liu, F.; Li, X.L.; Lin, T.; He, D.-W.; Wei, G.H.; Liu, J.H. \& Li, L.S. (2012): The cyclophosphamide metabolite, acrolein, induces cytoskeletal changes and oxidative stress in Sertoli cells. Molecular biology reports, 39: 493-500.

Lixin, X.; Lijun, Y. \& Songping, H. (2019): Ganoderic acid A against cyclophosphamide-induced hepatic toxicity in mice. Journal of biochemical and molecular toxicology, 33, e22271.

Moutsopoulos HM, Zampeli E, \& Vlachoyiannopoulos PG.: Medications, therapeutic modalities, and regimens used in the management of rheumatic diseases. in: Rheumatology in Questions. Springer, Cham, (2018);153-175.

Nair, S.; Manalil, J.; Ramavarma, S.; Suseela, I.; Thekkepatt, A. \& Raghavamenon, A. (2016): Virgin coconut oil supplementation ameliorates cyclophosphamideinduced systemic toxicity in mice. Human \& experimental toxicology, 35: 205-212.

Nile, S.H.; Keum, Y.S.; Nile, A.S.; Jalde, S.S. \& Patel, R.V. (2018): Antioxidant, anti-inflammatory, and enzyme inhibitory activity of natural plant flavonoids and their synthesized derivatives. Journal of biochemical and molecular toxicology, 32, e22002.

Okur, M.H.; Aydogdu, B.; Arslan, M.S.; Alabalik, U.; Arslan, S.; Kara, İ. et al. (2014): Intra-peritoneal administration of Ecballium elaterium diminishes postoperative adhesions. Acta cirurgica brasileira, 29: 639-643.

Phillips, C.; Francia, G.; Kerbel, R.S. \& Emmenegger, U. (2019):Personalized use of metronomic cyclophosphamide for DNA repair deficient castrationresistant prostate cancer: A phase II trial. Journal of Clinical Oncology. An American Society of Clinical
Oncology Journal. Published online February 26, 2019.

Prakash, C.; Kamboj, V.K.; Ahlawat, P. \& Kumar, V. (2015): Structural and molecular alterations in arsenicinduced hepatic oxidative stress in rats: a FTIR study. Toxicological \& Environmental Chemistry, 97: 14081421.

Raikhlin-Eisenkraft, B. \& Bentur, Y. (2000): Ecbalium elaterium (squirting cucumber)—remedy or poison? Journal of Toxicology: Clinical Toxicology, 38: 305-308.

Saker, M.M.; Farid, M.M.; Fahmi, A.A.; El-Mekkawy, S.A.; Taha, H.S. \& Amin, A.I. (2012): Large scale production of antitumor cucurbitacins from Ecballium Elaterium using bioreactor. African Journal of Biotechnology, 11: 12974-12982.

Salhab, A.S. (2013): Human exposure to Ecballium elaterium fruit juice: fatal toxicity and possible remedy. Pharmacology \& Pharmacy, 4(5): 447450.

Selvakumar, E.; Prahalathan, C.; Varalakshmi, P.; Kumarasamy, P. \& Saravanan, R. (2006): Modification of cyclophosphamideinduced clastogenesis and apoptosis in rats by $\alpha$-lipoic acid. Mutation Research/Genetic Toxicology and Environmental Mutagenesis, 606: 8591.

Shanmugarajan, T.; Arunsundar, M.; Somasundaram, I.; Sivaraman, D.; Krishnakumar, E. \& Ravichandran, V. (2008): Ameliorative effect of Ficushispida Linn. leaf extract on cyclophosphamide-induced oxidative hepatic injury in rats. J Pharmacol Toxicol, 3: 363-372.

Singh, C.; Prakash, C.; Tiwari, K.N.; Mishra, S.K. \& Kumar, V. (2018): Premna integrifolia ameliorates cyclophosphamide-induced hepatotoxicity by modulation of oxidative stress and apoptosis. 
Biomedicine \& Pharmacotherapy, 107: 634-643.

Suh, D.H.; Lee, H.W.; Jung, E.S.; Singh, D.; Kim, S.-H. \& Lee, C.H. (2017): In vivo metabolomic interpretation of the anti-obesity effects of hyacinth bean (Dolichos lablab L.) administration in high-fat diet mice. Molecular Nutrition \& Food Research, 61, 1600895.

Tipple, T.E. \& Rogers, L.K. (2012): Methods for the determination of plasma or tissue glutathione levels. Methods in molecular biology (Clifton, N.J.), 889: 315-324.

Tothova, C.; Nagy, O. \& Kovac, G. (2016): Serum proteins and their diagnostic utility in veterinary medicine: a review. Veterinární medicína, 61: 475-496.

Uslu, C.; Karasen, R.M.; Sahin, F.; Taysi, S. \& Akcay, F. (2006): Effect of aqueous extracts of Ecballium elaterium rich, in the rabbit model of rhinosinusitis. International journal of pediatric otorhinolaryngology, 70: 515-518.

Webster, D. (1974): A study of the interaction of bromocresol green with isolated serum globulin fractions. Clinica Chimica Acta, 53: 109-115.

Yesilada, E.; Tanaka, S.; Tabata, M. \& Sezik, E. (1989): Antiinflammatory effects of the fruit juice of Ecballium elaterium on edemas in mice. Phytotherapy Research, 3: 75-76.

Ylilmaz, K.; Karakuş, F.; Eyol, E.; Tosun, E.; Yiilmaz, İ. \& Ünüvar, S. (2018): Cytotoxic Effects of Cucurbitacin I and Ecballium elaterium on Breast Cancer Cells. Natural Product Communications, 13(11): 1445-1448.

Zarei, M. \& Shivanandappa, T. (2013): Amelioration of cyclophosphamideinduced hepatotoxicity by the root extract of Decalepis hamiltonii in mice. Food and chemical toxicology, 57: 179-184. 


\section{الملخص العربي}

خواص عصارة ثمرة القثاء البري المضادة للالتهاب والأكسدة ضد سمية السيكلوفوسفاميا على

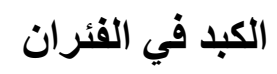

أسامة عبدالعزيز حسن" وميلاد جاد بولس"

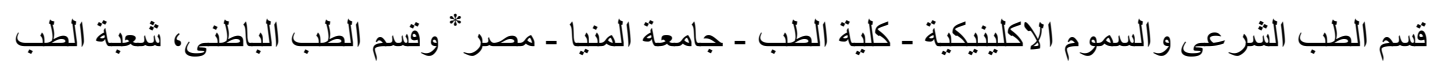

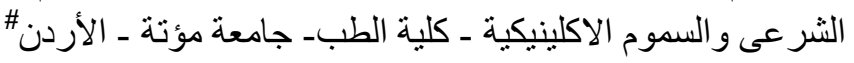

عقار السيكلوفوسفاميد هو أحد الأدوية المستخدمة فى العلاج الكيميائى و المثبط للمناعة وله آثار سامة متعددة وخاصة

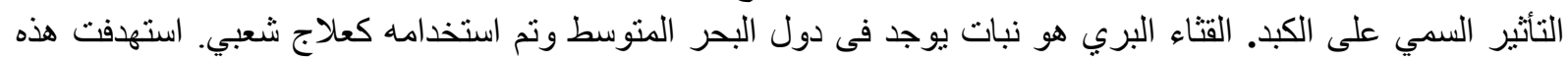

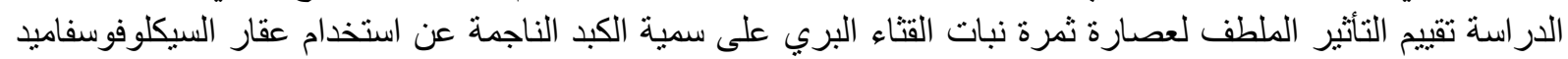

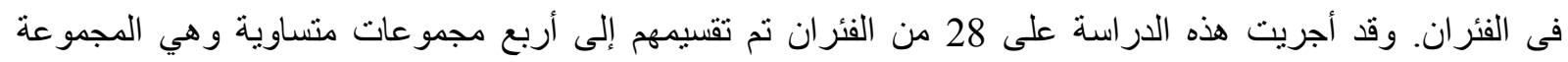

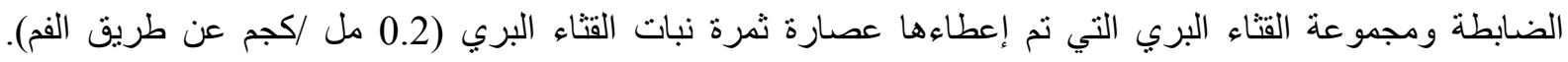

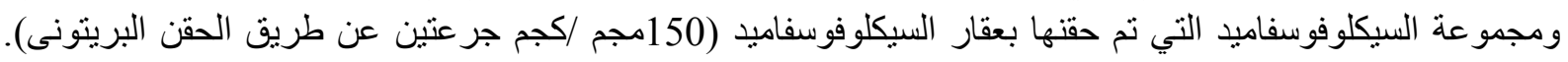

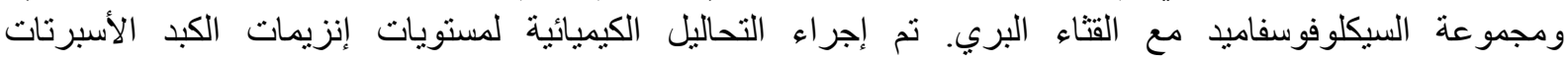

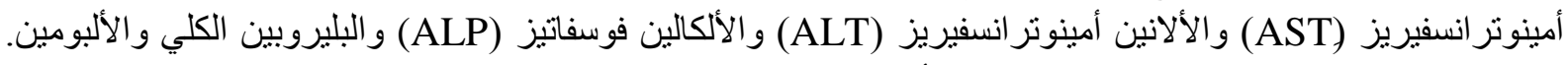

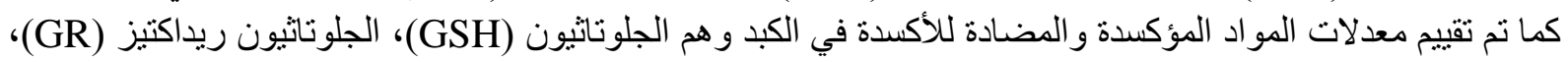

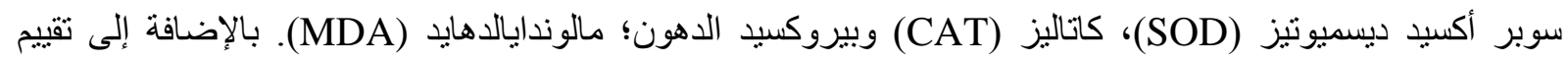
دلالات الالتهابات وهي عامل نخر الورم ألفا (TNF-

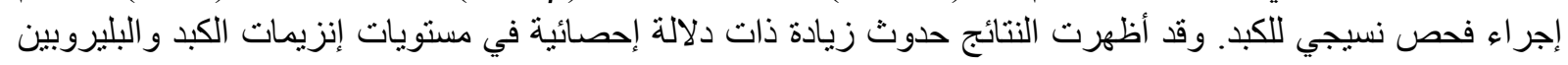

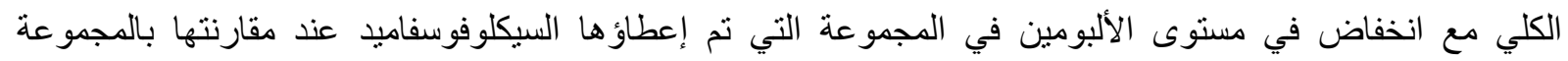

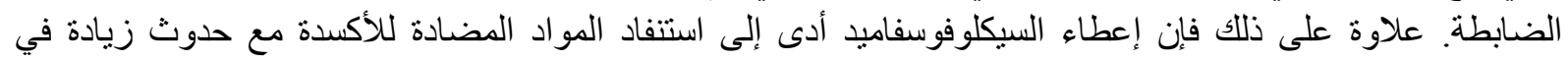

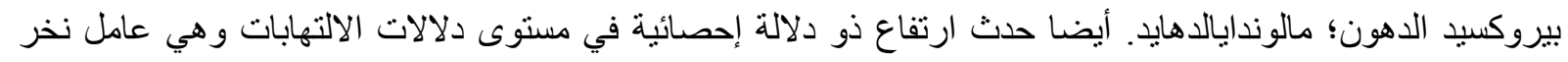

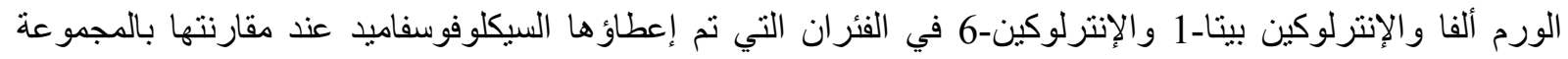

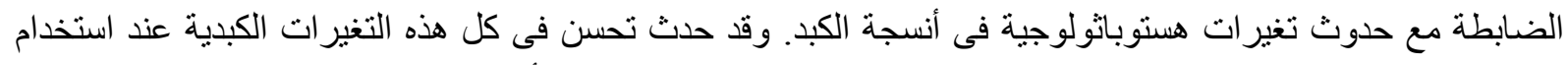

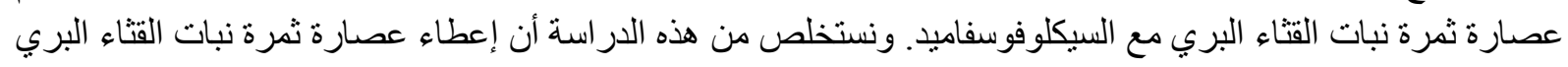

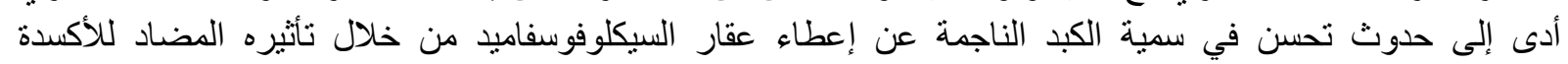
والالتهابات. 